
approches théoriques et méthodologiques

\title{
The Weight of Language and Action: Epistemic Stance, Methodological Action, and Theoretical Perspective in Knowledge Organization
}

Le poids du langage et de l'action dans l'organisation des connaissances : Position épistémologique, action méthodologique et perspective théorique

Joseph T. Tennis

\section{(2) OpenEdition}

Journals

Electronic version

URL: http://journals.openedition.org/edc/5710

DOI: 10.4000/edc.5710

ISSN: 2101-0366

\section{Publisher}

Université de Lille

Printed version

Date of publication: 1 December 2012

Number of pages: $15-40$

ISBN: 978-2-917562-08-6

ISSN: $1270-6841$

\section{Electronic reference}

Joseph T. Tennis, «The Weight of Language and Action: Epistemic Stance, Methodological Action, and Theoretical Perspective in Knowledge Organization », Études de communication [Online], 39 | 2012, Online since 01 December 2014, connection on 10 December 2020. URL : http:// journals.openedition.org/edc/5710 ; DOI : https://doi.org/10.4000/edc.5710

This text was automatically generated on 10 December 2020.

(c) Tous droits réservés 


\section{The Weight of Language and Action: Epistemic Stance, Methodological Action, and Theoretical Perspective in Knowledge Organization}

Le poids du langage et de l'action dans l'organisation des connaissances : Position épistémologique, action méthodologique et perspective théorique

Joseph T. Tennis

\section{Introduction}

1 Knowledge organization (KO) research is a field of scholarship concerned with the design, study and critique of the processes of organizing and representing documents that societies see as worthy of preserving (Tennis, 2008). In this context we are concerned with the relationship between language and action.

On the one hand, we are concerned with what language can and does do for our knowledge organization systems (KOS). For example, how do the words NEGRO or INDIAN work in historical and contemporary indexing languages? In relation to this, we are also concerned with how we know about knowledge organization (KO) and its languages. On the other hand, we are concerned with how to act given this knowledge. That is, how do we carry out research and how do we design, implement, and evaluate KO systems?

3 It is important to consider these questions in the context of our work because we are delegated by society to disseminate cultural memory. We are endowed with a perspective, prepared by an education, and granted positions whereby society asks us to ensure that documentary material is accessible to future generations. There is a social value in our 
work, and as such there is a social imperative to our work. We must act with good conscience, and use language judiciously, for the memory of the world is a heavy burden.

In this paper, I explore these two weights of language and action that bear down on KO researchers. I first summarize what extant literature says about the knowledge claims we make with regard to KO practices and systems. To make it clear what it is that I think we know, I create a schematic that will link claims (language) to actions in advising, implementing, or evaluating information practices and systems.

5 I will then contrast this with what we do not know, that is, what the unanswered questions might be (Gnoli, 2008; Dahlberg, 2011), and I will discuss them in relation to the two weights in our field of KO.

6 Further, I will try to provide a systematic overview of possible ways to address these open questions in KO research. I will draw on the concept of elenchus - the forms of epistemology, theory, and methodology in KO (Tennis, 2008), and framework analysis which are structures, work practice, and discourses of KO systems (Tennis, 2006). In so doing, I will argue for a Neopragmatic stance on the weight of language and action in KO (Rorty, 1982; 2000).

7 I will close by addressing the lacuna left in Neopragmatic thought - the ethical imperative to use language and action in a particular good and moral way. That is, I will address the ethical imperative of KO given its weights, epistemologies, theories, and methods. To do this, I will review a sample of relevant work on deontology in both western and eastern philosophical schools (e.g., Harvey, 1995).

8 The perspective I want to communicate in this section is that the good in carrying out KO research may begin with epistemic stances (cf., language), but ultimately stands on ethical actions. I will present an analysis describing the micro and the macro ethical concerns in relation to KO research and its advice on practice. I hope this demonstrates that the direction of epistemology, theory, and methodology in KO, while burdened with the dual weights of language and action, is clear when provided an ethical sounding board. We know how to proceed when we understand how our work can benefit the world.

9 KO is an important, if not always understood, division of labor in a society that values its documentary heritage and memory institutions. Being able to do good requires us to understand how to balance the weights of language and action. We must understand where we stand and be able to chart a path forward, one that does not cause harm, but adds value to the world and those that want to access recorded knowledge.

\section{Functioning as a KOS}

10 A large portion of the literature in KO is concerned with the functionality of the knowledge organization system (KOS). The ability for a KOS to function is linked to both its structure and semantics. The majority of critiques of KOS are that for one reason or another they do not represent language in a particular way, or that the structure of the KOS changes our interpretation of the language in a way that is unhelpful or untrue (we will get to the difference, as it is meaningful, below). This is why we must consider the weight of language in KOS. Action too is of concern, because if we want to study the function of a KOS we are studying one aspect of action. 
11 A KOS must function in some way, and we would like to think that research in KO helps us lead to a higher functionality of KOS either for everyone or for a particular group. If function is indeed linked to structure and semantics, and hence language and action, we must come to some epistemological understanding about structure, semantics, language, and action. This leads to the question of what we know and what we do not know in KO.

\section{What we know in knowledge organization}

12 It is very simple to sum up what we do know in KO. We know, both intellectually and not so intellectually, how to design and build knowledge organization systems (KOS). We know how to do this, because we know how to operate on particular assumptions about language and action. Our first and most basic assumption is that we can match words, concepts, and users' interests through terms and relationships between terms. The second assumption is that we believe by doing this we are organizing the knowledge represented in the written record. In a way, we already appreciate the weight of words and actions on our work. This weight is the measure of our success. However, we must ask whether or not we are actually organizing knowledge. Are we engaged in a simple act of organization? Are we implicit in others' self-determination or self-becoming? If that is what we are doing we have other considerations.

13 In the textbook approach to organizing knowledge, we need to understand the domain, understand the users, and chose the appropriate method for representing knowledge to them. There are, of course, differences of opinion on how to do this, and much of the contemporary literature on the theory of $\mathrm{KO}$ is pushing us beyond this textbook conceptualization (e.g., Feinberg, 2005).

\subsection{What we don't know in knowledge organization}

There are some key points we can identify in knowledge organization - points of indecision or lack of certainty. First, on what basis do we establish knowledge organization systems? The current majority of thinkers seem to follow the linguistic turn in social science research. This means that language is not absolutely referential, that is, we cannot trust that flowers always mean flowers in every context to every human being, at least not for the purposes of browsing, information retrieval, and sense-making. The domain-analytic, feminist, and rhetorical stances in $\mathrm{KO}$, for example, each assumes that particular words - say women - are not going to carry the same meaning, and therefore, not carry the same utility in different contexts. Thus, we cannot assume that the term WOMEN, has a set of characteristics essential to it in all contexts, and therefore can be used in the same relationship structure to other terms in a KOS.

However, this is not a universal approach to KO research in the field. There are many who assert that concepts (as a universal that cross language, culture, and time), is the proper object of study. In the latter's sense of research we are able to uncover knowledge units and use these in our work. Dahlberg claims:

I must underline that KO deals with language only incidentally as it primarily deals with concepts representing Knowledge Units. I have always defined such units in the following way: A Knowledge Unit (concept) is the synthesis of the essential characteristics of a referent to be represented by designations (terms, names, codes) (Dahlberg, 2011, p. 69). 


\section{can identify. If a concept has essential characteristics then, once we identify them we can} once and for all place that concept into relationship with others.

In this stance we see that we have to make the assertion that concepts are available to us no matter what form of investigation and no matter our culture. Thus, we should be able to, like Pasteur, find the microbes such that we can operate on them (Latour, 1999).

18 Gnoli calls the approaches informed by the Linguistic Turn epistemological approaches and those that posit essential characteristics of concepts ontological (Gnoli, 2008). He follows Poli $(1996,1997)$ when he says:

Ontology, in its philosophical meaning (not to be confused with the homonym schemes for machine treatment of semantic information), concerns the nature of the known things, especially in terms of the general categories to which they may belong. Issues like the subdivision of a class into kinds and parts, or the acknowledgment that a given concept consists of a process or a static entity, are ontological. Epistemology, instead, is about how humans know the world through their sense organs, and how they process knowledge according to categories both innate and culturally biased.

Knowledge is both epistemological and ontological, as it passes through human perception by its very nature, but also refers to real objects of the world having some intrinsic structure. However, authors in KO often emphasize either one or the other approach (Gnoli, 2008 p. 139).

\section{Epistemic Stance}

Elsewhere, I have defined epistemology, in the context of KO, as how we know:

In KO we make implicit epistemic statements about knowledge of concepts, acts (such as representation), entities, and systems. In so doing, we create knowledge, and our epistemic stance dictates what kind of knowledge that is. Some common names of epistemic stances are: pragmatic, positivistic, operationalist, referential, instrumental, empiricist, rationalist, realist, etc. Each of these makes claims as to what kind of knowledge can be created through research, and how it is gathered and how it is presented. These epistemic stances do this work because they have a systematic view on reality, our knowledge of it, and the meaning we can ascribe to it. The KO researcher that claims a pragmatic epistemic stance has made a statement against rationalist stances about the meaning of reality and how we come to know it (Tennis, 2008).

It is the epistemic stance that gives language and action weight. This is because epistemic stances craft the meaning of reality in relation to the only tools KOS have - words. We can imagine a variety of epistemic stances used in KO. For the sake of argument we can posit five different positions, and see where they fit in this divide between ontological and epistemological approaches. This will then lead us to the conclusions about weight in regards to language and action.

Before we can do this work, we have to define language and action more specifically. Language in KO is operationalized in three ways. First, we see language as terms in queries and terms in indexing languages. In this case, what matters is getting as close a match as possible (Salton and Buckley, 1991). Second, we see language in KO as a representation of what something is about or relevant to a set of documents or tasks. Wilson identifies this as the best textual means to an end (1968). So we are not concerned with matching letters on this level of language, we are trying to get at content. Here, the 
ontological and epistemological positions differ on the nature of this content. And this affects what we see as language on the third level.

In order to see either of these two levels (match and content), we must operate within an overlapping set of contexts. There are a number of ways to conceptualize these contexts. Work has been done on universes, domains, disciplines, communities of practice, etc. Each of these is a complementary conceptualization of how language works in these contexts. The important thing to consider in this instance is that language is indeed working in these contexts.

The ontological position will posit that because concepts are universals, any variation in language due to context must be acknowledged, but ignored. There is a permanent reality and transcends cultures. This universalizing interpretation of language (and more importantly what lies behind language), means that content is unchanging, identifiable, and can be fixed in relation to other content. This is because concepts and content are identical in the ontological position.

For the epistemological positions, language is not conceptualized as a one-for-one match or as content (the best textual means to an end), but rather language in context is a tool for more symbolic interaction. It is a way of solving problems in a complex environment the environment of what we know and do not know. So the work done is interpretation from matches and content. Blumer tells us that (1) human beings act toward things on the basis of the meanings they ascribe to those things, (2) the meaning of such things is derived from, or arises out of, the social interaction that one has with others and the society, (3) these meanings are handled in, and modified through, an interpretative process used by the person in dealing with the things they encounter (Blumer, 1969). Thus, the weight of this aspect of $\mathrm{KO}$, that is, the weight of language, on our work is quite heavy. We must move from matching letter sequences, to meaning, to symbolic interpretation.

25 We will find below that the three examples of epistemological positions take action in different ways in this context layer because each has a different standpoint in relation to meaning, others, and reinterpretation. Below I outline different responses to these three contextual layers.

\section{Action}

For our purposes, action is the process of doing something, typically to achieve an aim. In relation to $\mathrm{KO}$ and our conceptions of language in KO, action is how we go about interpreting, representing what we see as knowledge. It is the set of allowable interpretations and representations in the context of an information organization framework.

An information organization framework is a unit of analysis in knowledge organization that combines the KOS, the work practices that surround it, and the discourse of its implemented context (Tennis, 2006; Tennis and Jacob 2008). This unit of analysis contextualizes the concept of action. We triangulate action as an interplay between three things: (1) the work practice of interpreting and representing knowledge, (2) using a structure of a knowledge organization system (e.g., classification scheme, thesaurus, MARC encoding), (3) in a particular discourse. 

use Dialectical Critical Thinking, Foundationalist Pragmatism, Antifoundationalist Pragmatism, and Linguistic Relativism. Each of these makes claims about language and the action associated with knowledge organization. We will be able to see then the weight given to language and action from examining these positions.

31 A note about method is in order before I discuss these positions. The positions listed below are an incomplete list. They are also ideal types insofar as they are mostly hypothetical constructs useful in comparing different instances of the position. Therefore we can imagine, and even document, where different researchers in knowledge organization would vary slightly from these positions, or accept the majority of the claims of these positions, while still crafting their own unique position that varies slightly, in one particular way. We might also find contradictions in researchers' work in relation to these ideal typical positions. However, the purpose of using them is to try to identify the weight of language and action in carrying out and studying knowledge organization.

\subsection{Realism in Knowledge Organization (An Ontological Position)}

The position of realism proposes that concepts are the only real and constant. They are a universal. This means language, with its vagaries and diversity is a window onto something more real and fixed. The basic tenets of realism claim that concepts have essential characteristics that we can identify, and that those characteristics are fixed forever as part of the concept, regardless of context. This conception of language (and concepts) leads us to a particular set of actions. Once identified, essential characteristics will fix a concept into relationship with other concepts.

This means the action we take in identifying concepts and attributes essential to them, is a process of discovering a universal and its relationship to other universals. The implication of this is that there is one true correct organization of concepts and hence 
knowledge. The weight of language is heavy. We need to work quite hard to see the concept behind the terminology. We need to see, regardless of culture, the constant universal behind the confused and confusing variety of language.

There has been much work in KO in an effort to uncover these concepts in a realist manner (e.g., Richardson, 1901; Gnoli and Szostak, 2007). The desire to find constants is a practical one. If we were able to find constants, we would not have to reorganize document collections. We could simply add new classes as needed

\subsection{Dialectical Critical Thinking (An Ontological Position)}

Dialectical thinking, while often associated with the postmodernist movement, because of its use in feminist, post-colonial, and queer theory is not, in knowledge organization, an epistemological position, as one might assume. This is because the basic tenets of dialectical thinking are based on understanding a concept in relation to its opposite. This presupposes the need for there to be a constant relationship between two opposites - one that does not change. The dialectical critical thinker identifies this binary opposition, and tries to invert it, showing another possible way of being. An example of this position in KO research is some feminist work on hierarchy (Olson, 2007). In this case, we observe that man-reason/women-emotion are a paired binary in a constant relationship. This then allows us to critique this binary. Through critique we can imagine a new way of establishing permanent and constant relationships.

In the abstract then, the claims made by the dialectical critical thinking position is: (1) language is a window into concepts; (2) we only know concepts in relation to their opposites; (3) once we see the dialectic between concepts we can see their essential characteristics and the power relation between them (which is dominant); (4) once identified, essential characteristics will identify and fix a concept into relationship with other concepts; (5) and once identified, the dominance of one concept over another is inverted; (6) by using this method we will arrive at one true organization of concepts and hence knowledge that needs to be corrected to invert the dominance of one over the other; (7) once destabilized by this inversion, the process begins again, or if it is not destabilized, the critique continues.

In the context of KOS, we see dialectical critical thinking critique hierarchy as being constantly associated with patriarchy. This then requires a response on the part of the critical thinker. The response is to find an equally constant concept that is the opposite of hierarchy so that it is not associated with patriarchal domination, in order to emancipate those who are oppressed by the patriarchal systems of knowledge organization. In this case both hierarchy and its opposite have essential characteristics that are permanent and identifiable. The difference between this position and realism is that there is the need to identify dominance and destabilize that position in order to reach an emancipatory critique and way forward in knowledge organization design, implementation, and evaluation.

One caveat to the dialectical critical thinking position might be that once destabilized, the reality of concepts and essential characteristics can be rearranged or reinvented. That is, there is within dialectical critical thinking, the possibility of other ways of proceeding in organizing knowledge. However, this argument and path forward does not have any heft unless we posit the reality and hence the power of the dominant form of concept orientation (e.g., male vs. female and reason vs. emotion). We must also accept the 
corollary statement that any change would be real and not illusory, and would be based on essential characteristics of the concepts and knowledge that was emancipated from the dominant binaries. So while it is possible to imagine multiple realities, each with a different set of binaries, there is always a reality accessible to the editor of a KOS and representable in the KOS. There is also, each time we critique, an assumption of the correct way to organize knowledge. This is not based on a single eternal, but rather the most morally superior universal.

Thus the weight of language and action in this position is based on the power of language to shape the act of organization. In this case, language carries a heavy weight that can dominate some because every concept is understood only in relation to its opposite, and the presence of the opposite can be interpreted as a power relation of superior to inferior. The actions that follow are prescribed as just the opposite of the realist position. Instead of looking for universals to stabilize a KOS, dialectical critical thinking looks to find universals to turn them upside down, and must do so in the context of KOS. This is an interesting mandate for the design, implementation and evaluation of KOS. It implies constant change of recognized relationships between concepts while not changing the concepts. The upshot is that the attributes of these concepts are constantly renegotiating their affinities and dissimilarities, their accidental groupings and their intentional groupings. And if our purpose in designing a KOS is collocation of kinds, then we have a constantly shifting KOS.

\subsection{Foundationalist Pragmatism (An Ontological Position)}

40 This, the first type of pragmatism discussed, is a foundationalist pragmatism. This means we can establish truth claims about interpretation and representation in KOS. This is done through studying the group and its use of language. Domain analysis is the most popular term used in this context (Hjørland, 2002). The claims made by the foundationalist pragmatists are: (1) language shapes what we know only insofar as it allows us to do things in the world; (2) language is referenceable to a group of people (large or small) and their actions (we have confidence we can see that particular reality); (3) we can only know once we study this group, its language, and their actions (therefore there are multiple realities); (4) we can represent this group's use of language and therefore knowledge in our systems; (5) we have confidence in the language KOS designers used to represent the knowledge of this group because we observe them using the KOS to do their work.

41 This position seems to be very common in both current research and practice of KO. It is so common as to be considered commonsense by many working in the field. In this foundationalist position we assume that if we successfully identify the domain we can then see matches and content within the language of the domain and the interactions within the group. What follows is our belief that we trust the group in the domain can communicate and we can observe this communication with domain analysis. This in turn gives us confidence that we found the correct way of representing knowledge in our KOS. This is an ontological position because there is an explicitly wrong way to organize knowledge. If we ignore the domain and its interpretation of content then we are not organizing knowledge the correct way. It may not be essences we are discussing, but we are discussing attributes of concepts that fix them into relationship with one another in a particular context. 

(e.g., Gnoli, 2008), there is with any foundationalist argument, a need to situate research findings in truth claims. That is, they need to root their claim that they are constructing the correct KOS for a domain in a belief that this technique is better than others because it is the correct technique. What works is what is true in the foundationalist pragmatist position. This means there is both a right and a wrong way to construct a KOS. The antifoundationalist position does not have to do this.

\subsection{Antifoundationalist Pragmatism}

47 Antifoundationalist pragmatism is one of the reactions to the ontological positions. In the antifoundationalist stance there is no pressing concern to identifying what is true. The criterion of value is utility. The claims made in this position are: (1) Language shapes what we know only insofar as it allows us to do things in the world. (2) Language does not need to reference itself or the world; it needs to enable action in the world. (3) We have confidence in our use of language if we see it being utilized in knowledge organization systems. This seems very similar to the foundationalist position. However, we are not caught in the same binds as is the foundationalist when we take an antifoundationalist stance. The Wikipedia and the special classification conundrums do not hold. 
The problem with antifoundationalist claims is the link between truth claims and ethical action. Without anything to root claims about knowledge to, the antifoundationalist is free to take any moral or ethical stance. This has resulted in Rorty, for example, appealing to the concept of social hope, which states that we work communally to better the world (cf., Rorty, 2000). Even with Rorty's attempt at finding an ethical root, each antifoundationalist pragmatist has to round out his conceptions with their own. It is this that further distinguishes the two pragmatisms listed here. The former, the foundationalist pragmatism, does not necessarily need to make ethical claims about how to go about building KOS. The antifoundationalist does. We will return to this below.

There are others who do not see the difference between antifoundationalist and foundationalist pragmatisms. Dousa, after rehearsing some examples, tells us:

The foregoing examples indicate that, when $\mathrm{CP}$ and NP have been applied to methodological questions of KO design and research in the past, they have both been used to underwrite a perspectivist, constructivist, and anti-essentialist approach to KO. For this purpose, at least, they are functionally interchangeable (Dousa, 2010 p. 83-84).

particular case, Dousa claims that all pragmatisms are antifoundationalist. This is due to a difference in reading of the concept of antifoundationalist. It seems that Dousa and I do not agree on the definition of antifoundationalism as it is operationalized in the context of knowledge organization research. I take the definition that antifoundationalism is the opposite of foundationalism. Foundationalism is the view that we rest truth claims (knowledge) on justified belief. The antifoundationalist pragmatist does not need this justification. There is no burden to provide justification (the evidence for action). The foundationalist pragmatist is so burdened. In their appeal to reaching a truth claim, say about the language of a particular group, they have to study that group and provide evidence for their representation of the language of that group. Without evidence, the claims made by foundationalist pragmatists are hypotheses waiting for group consensus of some other form of evidence that can justify the hypothesis as a true belief.

In this case the weight of language and action is a moral weight. The words used are of unequal value because there are none that are better representations than others. Perhaps those that used more are somehow better, but not guaranteed to be the best because they are truly from, say a domain, or a faithful representation of an eternal concept. Instead the antifoundationalist pragmatist needs to provide utility for ethical purposes. The ethics come from another system. They do not inhere in this epistemological position. I will address this below.

\subsection{Linguistic Relativism}

The final position listed here is an example of linguistic relativism. This position is an epistemological position alongside antifoundationalist pragmatism. The claims of the linguistic relativist in KO research follow this pattern: (1) Language shapes what we know and how we know. (2) Language is internally referenceable (we cannot see a reality independent of the language used). (3) We can only know once we are inside this language system (therefore there are multiple realities). (4) We can only represent what the language is. (5) We have no confidence that words carry meaning or that we can understand another's meaning. 
This means we have no external access to the verifiability of the use of language in KOS. We must stand, as designers, implementers, and evaluators with only an approximation, and no surety, that we understand (interpreting) language and representing it in KOS such that others will understand it and act on it. Thus, there is nothing eternal or fixed. Examples of this kind of thinking are Wittgenstein's lion, Derridian readings of KOS, and unlimited semiosis in indexing (Mai, 2001).

\subsection{Comparative Weight of Language and Action in These Positions}

I outlined the five ideal types above in order to describe the weight of language and action advocated in these positions. I schematize these weights in Table 1.

Table 1: A schematic showing the weights of language and action in different positions

\begin{tabular}{|l|l|l|lr|}
\hline Position & Language & Action & $\begin{array}{l}\text { Characteristic of The } \\
\text { Weight }\end{array}$ \\
\hline Realism & Hides concepts & $\begin{array}{l}\text { Is permanent and } \\
\text { guided }\end{array}$ & Permanent heavy weight \\
\hline Dialectical Thinking & $\begin{array}{l}\text { Dominates and } \\
\text { must destabilize }\end{array}$ & $\begin{array}{l}\text { Is used to show } \\
\text { opposition }\end{array}$ & $\begin{array}{l}\text { Permanently } \\
\text { heavy weight }\end{array}$ \\
\hline $\begin{array}{l}\text { Foundationalist } \\
\text { Pragmatism }\end{array}$ & $\begin{array}{l}\text { Is only meaningful } \\
\text { in a context }\end{array}$ & $\begin{array}{l}\text { Is only meaningful } \\
\text { in a context }\end{array}$ & $\begin{array}{l}\text { Permanently } \\
\text { contextualized } \\
\text { weight }\end{array}$ \\
\hline $\begin{array}{l}\text { Antifoundationalist } \\
\text { Pragmatism }\end{array}$ & $\begin{array}{l}\text { Is a tool for action, } \\
\text { not meaning }\end{array}$ & $\begin{array}{l}\text { Is potentially } \\
\text { unethical }\end{array}$ & Permanently light weight \\
\hline Linguistic Relativism & $\begin{array}{l}\text { Obscures } \\
\text { knowledge }\end{array}$ & Is unguided & No weight \\
\hline
\end{tabular}

The weights outlined above are like anchors. They hold one to a commitment (or not as is the case of linguistic relativism) about the relationship between how we understand language and how we can design, implement, and evaluate information organization systems. We can see from the table that if we took a strictly foundationalist pragmatic position, we could only speak to one domain or context. The anchor is not so heavy. However, it also may or may not last: as the domain changes its use of language so too must the KOS, otherwise it is incorrect. Realism and dialectical critical thinking will always have a fixed concept to work from, and so will not require revision on a semantic level. Having said that, dialectical critical thinking will reorganize the structure of KOS to destabilize the dominant relationship between accepted mainstream and fringe elements. Neither antifoundationalist pragmatism nor linguistic relativism has a heavy weight. They are not concerned with what is correct; rather one is concerned with what is useful and the other with what is faithful but unsure. The faithful but unsure stance is like a KO Dadaism. Since meaning is not available, we can do nothing but paint with the given words, arranging terms in relation to one another conceptualized as a performance that may or may not carry meaning. Our access to fixity is an illusion for the linguistic 
relativist, so we operate with the tacit assumption that what we do is as good as we can do, simply because we have no other choice.

\section{Language and Action and The Concepts of Useful and Correct}

57 From the discussion of positions and weights above, we can see that there is a very different set of requirements about the value of KOS in different positions. We have from the realist and dialectical critical thinker the need to be correct in KO. So too must we be correct in foundational pragmatism. If we are correct, our KOS will represent a reality that we believe will then offer users a better entré into the written record. There are two problems with the need for KOS to be correct. First, we must be able in this case to account for everything. Second, if we believe we are correct, we are correct permanently. That is, nothing can or should change in our KOS. Let us take each of these in turn.

58 If we want to assure that our KOS are correct we must account for everything because KOS are not just simply concepts listed, but concepts listed in relation to one another. In the realist position, those relationships are defined by understanding essential attributes and then fixing those attributes in relation to one another. The relationships then, in the realist stance, are as permanent as the concepts. Should anything be added to the set of concepts then the relationships would change. This is because the concept would only be known by its essential attributes, and those would have to be different from what was already in the set. If we have different attributes, then we have different relationships, and therefore we were not correct before, and have to revise our KOS accordingly.

The second criticism has to do with this revision. If we believe that our KOS should reflect a reality (as the first three listed above do), we expect there to be some fixity. However, as is well documented in the history of KOS things change (Boydens and Hooland, 2011; Buckland, 2012; Shamurin, 1967; Tennis, 2012). Thus, one is only correct at one point in time. To the foundationalist pragmatist this, on the surface, is not a problem. If the domain or context changes, we can and should change our KOS. The problem comes to the forefront when we think about how often a KOS should change. Is there an acceptable period of incorrect KOS for the foundationalist pragmatist? How does that caveat get written into the position? What justification can be offered that is in line with this ontological position which states a KOS can have parts that are correct and incorrect, and for how long?

It is questions like these that lead me to advocate for an antifoundationalist pragmatism. If we are not concerned with correct, but rather with useful, then we do not have to address the issues of totality - knowing all of the attributes of concepts at one point in time. Nor are we as preoccupied with change. We would expect change in the context of an antifoundationalist approach. This is because utility is contextualized by action and how we interact with KOS - not with the language of a domain. The concerns of an antifoundationalist approach are not the separation between what is correct and what is incorrect. Rather, the antifoundationalist approach prioritizes and therefore is only concerned with two things: (1) vocabulary to cope with the world (in our case through access to the written record), (2) guided by the hope that coping with the world will appeal to our sociality (Rorty, 2000). 
61 If we ask our KOS to help us cope with the world, rather than being correct, I think we have set up our design, implementation, and evaluation desiderata in a workable context, free from epistemic traps. What remains to consider is the ethics of utility. To whom should a KOS be useful?

\section{Ethics and Knowledge Organization Research}

We can now return to the social value and the social imperative to our work. There are many ethical systems one could bring to KO research. For some, the dialectical critical thinking mentioned above carries with it its own ethical commitment to destabilize dominant discourses to enable emancipatory possibilities (Craib and Benton, 2010). However, this could be said of almost all of the approaches above. All of the ontological approaches seem to reveal a belief that if we can identify the real we can identify the moral. In the context of realism, we believe in a natural ecology of attributes in relation to one another, so we see a moral order in that. This is evidenced in the systems built out of realist work like the ICC (Dahlberg, 2008). In these schemes we see the privileging of particular spiritual products as the ultimate in accumulation of attributes. This presupposes the eternal existence of such spiritual attributes, a claim that is disputed. Likewise, the dialectical critical thinkers claim that eternal concepts that hold a dominant position are ethically unjust because they marginalize and therefore suffocate the possibility of a true democracy (Craib and Benton, 2010). Both of these commitments come from the weight of language and action in the context of designing, implementing, and evaluating KOS.

The antifoundationalist stance hopes for some ethical guidance, but does not provide any. Without a foundation like those mentioned above, we have no roots, per se in the antifoundationalist stance on KOS. We must import an ethics. And this is not an easy thing to do.

64 For my purposes, I have begun to work with a Buddhist ethics of intention and harm. This is of course a particular commitment, one that is linked to an ontology and epistemology of Buddhism. This could pose a problem for the antifoundationlist, if she was interested in disavowing anything with foundational roots. However, that is not the character of an antifoudnationalist stance. This ethics is a useful conceptualization of how to work toward an ethical utility - one that is not permanent or fixed, but unfolds in the acts of knowledge organization as a way to act intentionally and with consciousness about harm in KOS.

\subsection{Intention in Buddhist Ethics}

65 In the context of Buddhism, philosophers have been concerned with intentional action. When we claim that we are going to reduce or eliminate harmful actions, we must step back and ask how to do this. For example, if we vow to cause no harm, what are we doing when we step on an ant while walking down the street? Some Buddhist thinkers have considered this in the context of levels of intention. There are accidental actions (without intention), and there are different kinds of intentional actions - those that increase our sense of sociality and those that do not (Harvey, 1995). Those that increase our sociality are contingent and contextual insofar as there are many different constructs that we can examine in relation to social interaction (cf. Blumer, 1969). For the Buddhist thinker they 
are concerned with right action, the ability to carry out the everyday course of being without causing harm. Thus, they look inward to see how their mind and action align or do not align. This fits nicely within the context of the antifoundationalist stance outlined above.

It is this kind of constant questioning of intention that is key to the ethical stance we can take in relation to KOS. If we adopt an antifoundationalist stance, then we are not rooted in a correct way to interpret and represent language; rather we are admitting of the intensely social, and intimately impermanent work of interpretation and representation for society. KOS then are designed for utility, and evaluated on their intentionality.

For foundationalist thinkers, intentionality is not required of the KO researcher to consider. For them we can see the reality of concepts and we can faithfully represent those concepts in our KOS, and intention is elided because we are simply offering up reality. We do not intend to do anything but that, so there is no need to perseverate on actions. All of the weight is in language, whereas the antifoundationalist sees weight in the actions - specifically ethical actions.

\subsection{Intentionality and Utility}

68 If we adopt an antifoundationalist stance we need an ethical stance. Buddhist ethics of action and intention offer us such a tool. We then see that the design, implementation, and evaluation is a marriage of intentionality and utility. We design intentionally for utility, we question our implementation based on intentionality and accident, and we evaluate our KOS based on utility alongside its ability to increase sociality and reduce harm.

\section{Epistemic Stance, Methodological Action, and Theoretical Perspective in Knowledge Organization}

Though there are competing theories of theory (Smiraglia, 2002; Mai, 2002; Tennis 2008), epistemic stances (Gnoli, 2008; Hjørland 1997), and methodology, we can begin now to reflect on the weight of language and action in the context of KOS.

What I have tried to present here is a comparative analysis, using ideal types of positions, both ontologically and epistemologically focused. In so doing, I have characterized their commitments to language and action. From the examples presented we can see that if we root our commitments about language to uncovering the correct way we feel assured in our ethical stance toward KOS. However, we have problems with this because our claim to verisimilitude leads us to problems of seeing the whole universe and the whole universe over time. Antifoundationalist approaches do not have the same problems. They are not concerned with the correct, but with the useful. This means we can eschew the problems of the foundationalists. This, however, leads to problems of ethics. Here I have introduced, albeit briefly, a conception of intention in relation to the antifoundationalist thought. The weight then is on action for the antifoundationalist, not language - the opposition of the foundationalist thinkers. 


\section{Concluding Remarks}

71 Knowledge organization is an important, if not always understood, division of labor in a society that values its documentary heritage and memory institutions. Being able to do good requires us to understand how to balance the weights of language and action. We must understand where we stand and be able to chart a path forward, one that does not cause harm, but adds value to the world and those that want to access recorded knowledge.

This paper examined what we know now (according to my reading), and how we might move forward in the realm of epistemology, theory, and methodology by considering the ethical dimension of our work couched, as it is, in a deep concern for our knowing knowledge and how it should be organized.

73 It is our work, to date, to know how to organize knowledge the right way; now, perhaps by reflecting on epistemology, theory, and methodology we can act with both knowledge and intention. That is, perhaps we can balance the weight of language and action with a solid fulcrum of ethics and intention.

\section{BIBLIOGRAPHY}

References

Bliss, H. E., (1939), The Organization of Knowledge in Libraries and the Subject Approach to Information, $2^{\text {nd }}$ Ed, New-York, H. W. Wilson.

Blumer, H., (1969), Symbolic Interactionism: Perspective and Method, Los Angeles, University of California Press.

Boydens, I. and van Hooland, S., (2011), « Hermeneutics applied to the quality of empirical databases ", Journal of Documentation vol. 67, no 2, p. 279-289.

Brooks, J., \& Hofer, H. C., (1976), Sexual Nomenclature: A Thesaurus, Boston, G. K. Hall.

Buckland, M. K., (2012), « Obsolescence in Subject Description ». Journal of Documentation, vol. 68, no 2, p. 154-161.

Craib, I. and Benton, T., (2010), Philosophy of Social Science: The Philosophical Foundations of Social Thought, 2nd ed., Palgrave MacMillan.

Dahlberg, I., (2008), « The Information Coding Classification (ICC): A Modern, Theory-Based FullyFaceted, Universal System of Knowledge Fields ». Axiomathes no 18, p. 161-176.

Dahlberg, I., (2011), « Brief Communication: How to Improve ISKO's Standing: Ten Desiderata for Knowledge Organization », Knowledge Organization, vol. 38, no 1, p. 68-74.

Dousa, T. M., (2010), « Wither Pragmatism in Knowledge Organization? Classical Pragmatism vs. Neopragmatism as KO Metatheories ", in Proceedings of the 11th International Conference for Knowledge Organization, Rome, Italy, 2010, Würzburg, Ergon, p. 78-84. 
Feinberg, M., (2005), « Expression of feminism in three classifications », Advances in classification research, Medford, NJ, Information Today.

Gnoli, C., (2008), « Ten long-term research questions in knowledge organization », Knowledge Organization vol. 35, no 2/3, p. 137-149.

Gnoli, C. and Szostak, R., (2007), The Léon Manifesto. Available at http://www.iskoi.org/ilc/ leon.php.

Harvey, P., (1995), «Criteria for Judging the Unwholesomeness of Actions in the Texts of Theravada Buddhism », Journal of Buddhist Ethics, no 2, p. 140-151.

Hjørland, B., (1997), Information Seeking and Subject Representation: Activity-Theoretical Approach to Information Science, Westport, Conn., Greenwood Press.

Latour, B., (1999), Pandora's Hope, Cambridge, Mass., Harvard University Press.

Mai, J-E., (2001), « Semiotics and indexing: an analysis of the subject indexing process », Journal of documentation, vol. 57 no 5, p. 591-622.

Mai, J-E., (2002), « Is classification theory possible? Rethinking classification research », in Challenges in knowledge representation and organization for the 21st century: Integration of knowledge across boundaries: Proceedings of the Seventh International ISKO Conference 10-13 July 2002 Granada, Würzburg, Ergon, p. 427-78.

Miksa, F., (1998), The DDC, The Universe of Knowledge, and the Post-Modern Library, Albany, NY, Forest Press.

Olson, H.A., (2007), « How We Construct Subjects: A Feminist Analysis », Library Trends, vol. 56, no 2, p. 509-541.

Poli, R., (1996), « Ontology for knowledge organization », in Knowledge organization and change: Proceedings of the Fourth International ISKO Conference, 15-18 July 1996 Washington, DC, Würzburg, Ergon, p. 313-319.

Poli, R., (1997). « Framing ontology », in Corazzon, Raul, ed., Ontology: A resource guide for philosophers, Available at http://www.formalontology.it/essays/framing.pdf.

Richardson, E. C., (1901), Classification: Theoretical and Practical.

Rorty, R., (1982), Consequences of Pragmatism, Minneapolis, Minn., University of Minnesota Press.

Rorty, R., (2000), Philosophy and Social Hope, New York, Penguin.

Salton, G. and Buckley, C., (1991), « Global Text Matching for Information Retrieval », Science, vol. 253, no 5023, p. 1012-1015.

Shamurin, E. I., (1967), Geschichte der bibliothekarisch-bibliographischen Klassifikation, 2 vols., München, Verlag Dokumentation.

Smiraglia, R. P., (2002), « The Progress of Theory in Knowledge Organization », Library Trends, vol. 50, no 3, p. 330-349.

Tennis, J. T., (2006), « Function, Purpose, Predication, and Context of Information Organization Frameworks », in Knowledge Organization for a Global Learning Society: Proceedings of the 9th International Conference for Knowledge Organization. International Society for Knowledge Organization, Vienna, Austria, July 5-7, 2006, Würzburg, Ergon, p. 303-310.

Tennis, J. T., (2008), « Epistemology, Theory, and Methodology in Knowledge Organization: Toward a Classification, Metatheory, and Research Framework », Knowledge Organization vol. 35, no $2 / 3$, p. 102-112. 
Wilson, P., (1968), Two Kinds of Power: An Essay on Bibliographical Control, Berkeley, University of California Press.

\section{ABSTRACTS}

In this paper, I explore two weights of language and action that bear down on KO researchers. I first summarize what extant literature says about the knowledge claims we make with regard to KO practices and systems. I then contrast this with what we do not know, that is, what the unanswered questions might be, and I discuss them in relation to the two weights in our field of KO. I close with a discussion of the ethical imperative of KO given its weights, epistemologies, theories, and methods. To do this, I review a sample of relevant work on deontology in both western and eastern philosophical schools.

Dans cet article, j'examine les deux poids que sont le langage et l'action dans le travail des chercheurs en OC. Je résume d'abord ce que la littérature actuelle dit de ce que nous affirmons savoir des pratiques et systèmes d'organisation des connaissances. Je contraste ensuite ce que nous pensons savoir à ce que nous ne savons pas, autrement dit les questions pour lesquelles nous n'avons pas de réponse, et j'analyse leur relation aux deux poids du langage et de l'action dans le domaine de l'OC. Je termine avec une discussion des impératifs éthiques de l'oc étant donné les poids, épistémologies, théories et méthodologies qui la caractérisent. Pour ce faire, je passe en revue un échantillon de travaux pertinents sur la déontologie dans les écoles de philosophie occidentales et orientales.

\section{INDEX}

Keywords: knowledge organization, antifoundationalism, epistemology, foundationalism, intention

Mots-clés: organisation des connaissances, antifondationalisme, épistémologie, fondationalisme, intention

\section{AUTHOR}

\section{JOSEPH T. TENNIS}

University of Washington Seattle, Washington, USA 